\title{
Study of CdZnTeSe Gamma-Ray Detector under Various Bias Voltages
}

\author{
Mebougna L. Drabo', Stephen U. Egarievwe'2,3,4, Utpal N. Roy ${ }^{4,5}$, Benicia A. Harrison', \\ Carmella A. Goree6, Emmanuel K. Savage ${ }^{7}$, Ralph B. James ${ }^{5}$
}

\author{
${ }^{1}$ Department of Mechanical \& Civil Engineering, and Construction Management, Alabama A\&M University, \\ Huntsville, AL, USA \\ ${ }^{2}$ Nuclear Engineering and Radiological Science Center, Alabama A\&M University, Huntsville, AL, USA \\ ${ }^{3}$ Department of Electrical Engineering and Computer Science, Alabama A\&M University, Huntsville, AL, USA \\ ${ }^{4}$ Department of Nonproliferation and National Security, Brookhaven National Laboratory, Upton, NY, USA \\ ${ }^{5}$ Science and Technology Directorate, Savannah River National Laboratory, Aiken, SC, USA \\ ${ }^{6}$ Biological and Environmental Sciences Department, Alabama A\&M University, Huntsville, AL, USA \\ ${ }^{7}$ Department of Physics, Chemistry and Mathematics, Alabama A\&M University, Huntsville, AL, USA \\ Email: mebougna.drabo@aamu.edu
}

How to cite this paper: Drabo, M.L., Egarievwe, S.U., Roy, U.N., Harrison, B.A., Goree, C.A., Savage, E.K. and James, R.B. (2020) Study of CdZnTeSe Gamma-Ray Detector under Various Bias Voltages. Materials Sciences and Applications, 11, 553-559. https://doi.org/10.4236/msa.2020.118036

Received: June 7, 2020

Accepted: August 2, 2020

Published: August 5, 2020

Copyright $\odot 2020$ by author(s) and Scientific Research Publishing Inc. This work is licensed under the Creative Commons Attribution International License (CC BY 4.0).

http://creativecommons.org/licenses/by/4.0/

\begin{abstract}
Cadmium zinc telluride selenide ( $\mathrm{CdZnTeSe}$ ) is a new semiconductor material for gamma-ray detection and spectroscopy applications at room temperature. It has very high crystal quality compared to similar materials such as cadmium telluride and cadmium zinc telluride. The consistency of peak position in radiation detection devices is important to practical applications. In this paper, we have characterized a CdZnTeSe planar detector for bias voltages in the range of $-20 \mathrm{~V}$ to $-200 \mathrm{~V}$ and amplifier shaping time of 2,3 and 6 $\mu$ s. The peak position of the $59.6-\mathrm{keV}$ gamma line of ${ }^{241} \mathrm{Am}$ becomes more stable as the absolute value of the applied voltage increases. The best energy resolution of $8.5 \%$ was obtained for the $59.6-\mathrm{keV}$ gamma peak at $-160 \mathrm{~V}$ bias voltage and $3-\mu$ s shaping time. The energy resolution was relatively stable in the $-120 \mathrm{~V}$ to $-200 \mathrm{~V}$ range for a $6-\mu$ s shaping time. Future work will be focused on the study of the peak position and energy resolution over time.
\end{abstract}

\section{Keywords}

CdZnTeSe, Energy Resolution, Energy-Peak Stability, Gamma-Ray Spectroscopy, Nuclear Detectors

\section{Introduction}

Cadmium zinc telluride selenide (CdZnTeSe or CZTS) has shown great promise 
as a semiconductor material for fabricating cheaper gamma-ray detection and spectroscopy devices for applications at room temperature (i.e., without cryogenic cooling), compared to similar materials like cadmium telluride (CdTe) and cadmium zinc telluride (CdZnTe of CZT) [1] [2] [3] [4]. This advantage comes from the high crystal uniformity of CZTS compared to CdTe and CZT [2] [3]. A material with higher crystal uniformity and lesser defects will give more detector-grade wafers per volume of the as-grown ingot. Presently, CdTe and CZT have applications in gamma-ray spectroscopy, medical imaging, nuclear and radiological threat detection, and astrophysics. CZTS has the potential of reducing the cost of fabricating devices that could be used in these applications.

The stability of peak position and energy resolution in radiation detection devices are important for practical applications in radiation detection, spectroscopy, and imaging. Pérez et al. [5] studied the stability of CZT coplanar detectors over a period of four months. Shifts of about $0.5 \%$ in the photopeak positions were observed for the $662-\mathrm{keV}$ gamma line of ${ }^{137} \mathrm{Cs}$ with the detectors maintained at a temperature of $22.5^{\circ} \mathrm{C} \pm 1.0^{\circ} \mathrm{C}$ and electronic experimental parameters kept fixed [5]. Similar results were obtained for the $356-\mathrm{keV}$ peak of ${ }^{133} \mathrm{Ba}$ and $1173-\mathrm{keV}$ peak of ${ }^{60} \mathrm{Co}$ [5]. Degradation of energy resolution over time was observed, and fluctuations in the energy resolutions of the $356-\mathrm{keV}$ peak of ${ }^{133} \mathrm{Ba}$ and $1173-\mathrm{keV}$ peak of ${ }^{60} \mathrm{Co}$ were higher than that of the ${ }^{137} \mathrm{Cs} 662-\mathrm{keV}$ peak [5]. It was concluded that increases in bias voltage and operating temperature led to a significant increase in noise, which had a greater effect on the low-energy peaks due to the smaller signal-to-noise ratio [5].

Egarievwe et al. [6] studied the detection and electrical properties of CZT at elevated temperatures, where the energy resolution of the $31-\mathrm{keV}$ peak of ${ }^{133} \mathrm{Ba}$ was observed to be $16 \%, 18 \%, 28 \%$ and $38 \%$ at $24^{\circ} \mathrm{C}, 30^{\circ} \mathrm{C}, 40^{\circ} \mathrm{C}$ and $50^{\circ} \mathrm{C}$ respectively. The $31-\mathrm{keV}$ peak position varied within $3 \mathrm{keV}$ at $70^{\circ} \mathrm{C}$ at an applied bias of $60 \mathrm{~V}$. For bias voltages from 20 to $100 \mathrm{~V}$, the fluctuation in the energy resolution was between $15 \%$ and $18 \%$ at $25^{\circ} \mathrm{C}$ and between $22 \%$ and $38 \%$ at $50^{\circ} \mathrm{C}$. Studies involving cooling were carried out by Chun et al. [7] where an improvement of about $2 \%$ was recorded for the energy resolution from $30^{\circ} \mathrm{C}$ to $-40^{\circ} \mathrm{C}$ for the $122-\mathrm{keV}$ and $136-\mathrm{keV}$ peaks of ${ }^{57} \mathrm{Co}$. Mæhlum et al. [8] studied $5 \times$ $5 \mathrm{CZT}$ detector modules under variations of temperature $\left(20^{\circ} \mathrm{C}-40^{\circ} \mathrm{C}\right)$ and humidity (relative humidity $10 \%-70 \%$ ), where they recorded an average photopeak variation of $\pm 1 \mathrm{keV}$ for the $122 \mathrm{-keV}$ peak of ${ }^{57} \mathrm{Co}$ over a period of 248 days. In this paper, we present results on the study of the stability of the energy-peak position for a CdZnTeSe planar detector over an operating voltage range of -20 to $-200 \mathrm{~V}$. We also report on peak position changes based on the amplifier shaping time.

\section{Experiments}

A planar detector of size $4.65 \times 7.00 \times 2.70 \mathrm{~mm}^{3}$ was fabricated from as-grown CZTS crystal. The $\mathrm{Cd}_{1-\mathrm{x}} \mathrm{Zn}_{\mathrm{x}} \mathrm{Te}_{1-\mathrm{y}} \mathrm{Se}_{\mathrm{y}}$ crystal, with $\mathrm{x}=0.1$ and $\mathrm{y}=0.04$, was grown 
by the traveler heater method [9]. The CZTS wafer was cut from the ingot using a diamond impregnated wire was. It was then polished using an 800-grit silicon carbide paper. This was followed by successively polishing with 100-grit and 1200-grit silicon carbide papers. Subsequent polishing on MultiTex pads with varying sizes $(3.0-0.1 \mu \mathrm{m})$ of alumina powder was made to smoothen the wafer surfaces. After polishing, the wafer was rinsed with distilled water and dried with compressed air. Gold contacts were deposited on the two opposite $4.65 \times 7.00$ $\mathrm{mm}^{2}$ sides of the wafer using the electroless deposition method.

Current-voltage (I-V) measurements were made prior to detector testing to determine the resistivity of the CZTS material. A special aluminum box equipped with Keithley Picoammeter and Voltage Source (model number 6487) was used in the I-V measurements to ensure that the CZTS wafer has high resistivity. After establishing a high resistivity on the order of $10^{10} \Omega-\mathrm{cm}$, the wafer was mounted in a customized sample holder made by eV Products (now Kromek). The cylindrical-shaped sample holder is made of brass, and it has a beryllium window for placing a sealed radiation source. The holder is connected to a high voltage supply and a pre-amplifier that is connected to a multichannel analyzer (MCA) and amplifier. The MCA is connected to a computer that has software for recording the energy spectrum of radiation sources. An ${ }^{241} \mathrm{Am}$ radiation source was used in this experiment. Various applied bias voltages in the range of $20-200 \mathrm{~V}$ were used. The coarse gain of the amplifier was kept at 500, and measurements were made at 2, 3 and $6 \mu$ shaping time. The spectrum of the detector response to ${ }^{241} \mathrm{Am}$ radiation source was very poor.

\section{Results}

The current-voltage curve of the CZTS detector in the -200 to $200 \mathrm{~V}$ range is shown in Figure 1. The resistivity determined from the I-V curve is on the order of $10^{10} \Omega$-cm.

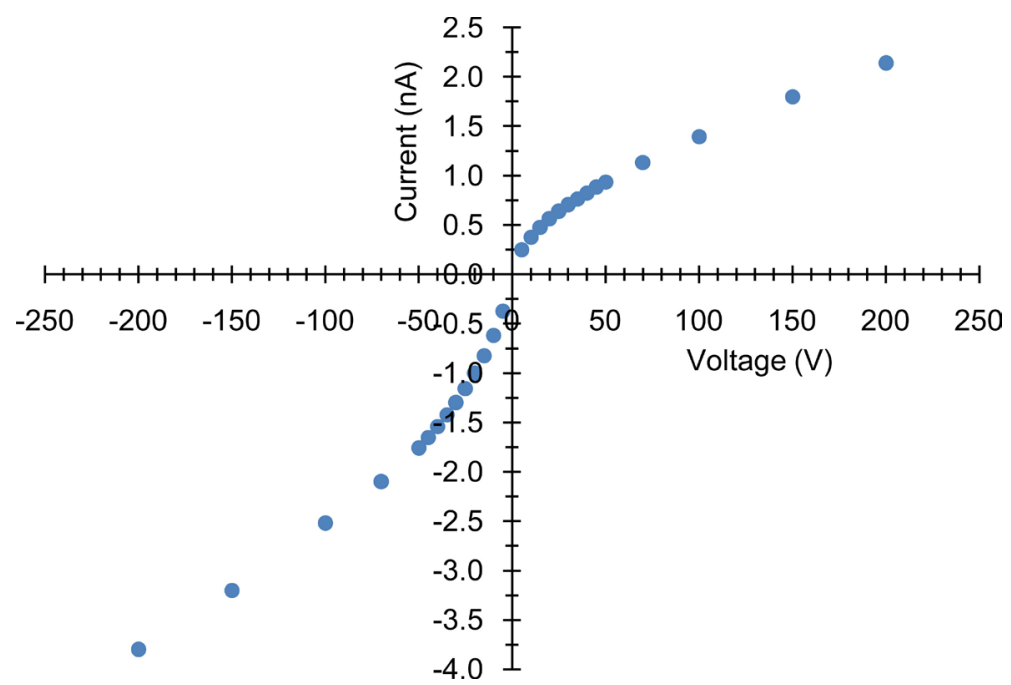

Figure 1. The current-voltage characteristics of the CZTS detector in the -200 to $200 \mathrm{~V}$ range. Extracted from the same dataset in [4]. 
The best detector responses to an ${ }^{241} \mathrm{Am}$ sealed radiation source for shaping time of $2 \mu \mathrm{s}, 3 \mu \mathrm{s}$ and $6 \mu$ s are shown in Figure 2. The energy resolution is reported as the full-width-at-half-maximum (FWHM) of the 59.6-keV photopeak.

The best energy resolution of $8.5 \%$ was at an applied bias of $-160 \mathrm{~V}$ and shaping time of $3 \mu$ s. The energy resolution for various applied bias voltages and shaping times are shown in Table 1 . The variation in energy resolution, computed as the difference between the maximum and minimum resolutions, is minimum for the $6-\mu$ s shaping time, and it is $1.7 \%$. The variations are $2.5 \%$ for 3 - $\mu$ s shaping time and $3.6 \%$ for $2 \mu \mathrm{s}$. The peak positions for the $59.6-\mathrm{keV}$ gamma
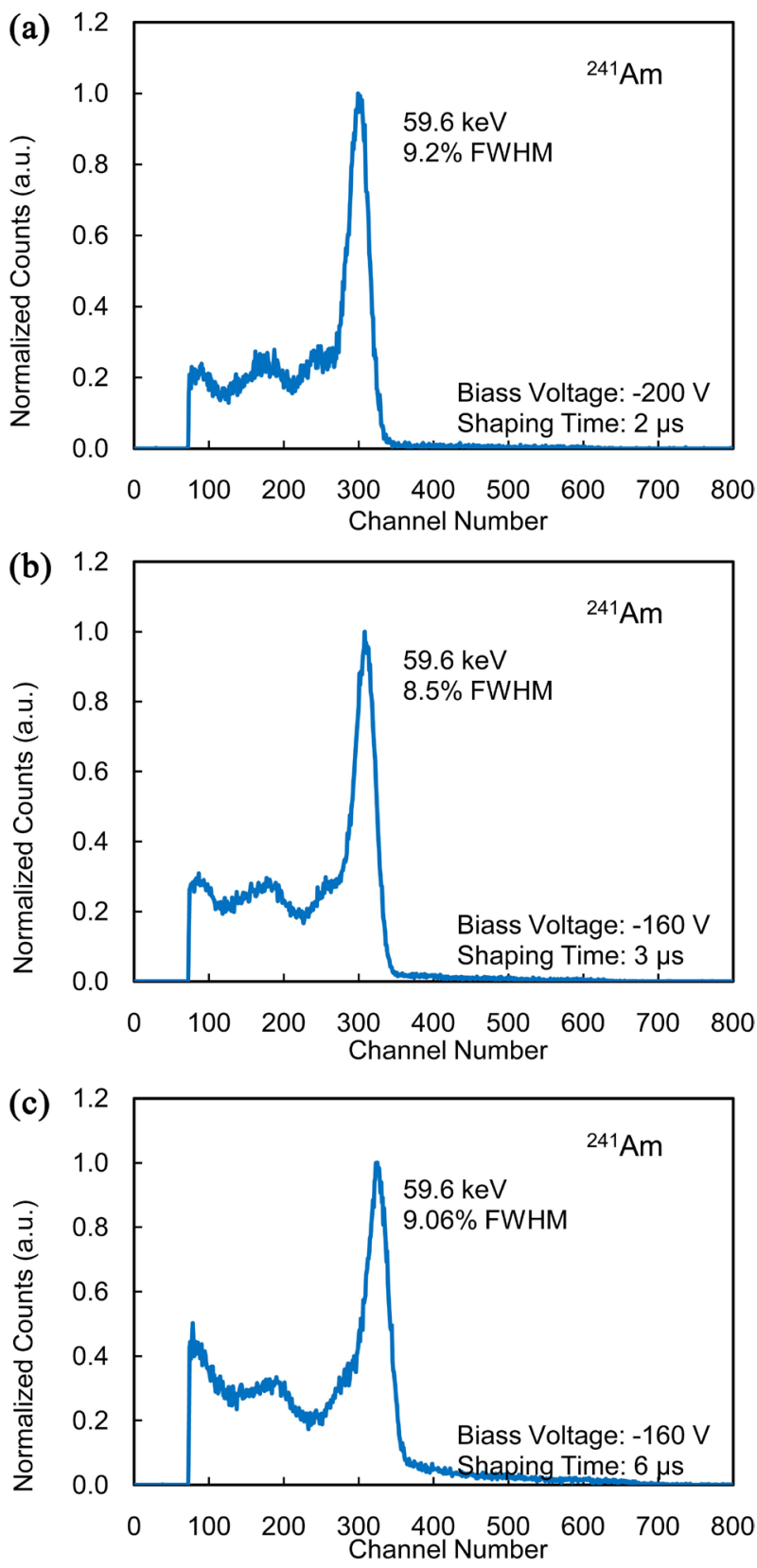

Figure 2. CZTS detector response to ${ }^{241} \mathrm{Am}$ at an applied bias of $-160 \mathrm{~V}$ and shaping time of (a) $2 \mu \mathrm{s}$, (b) $3 \mu \mathrm{s}$ and (c) $6 \mu \mathrm{s}$. 
line of ${ }^{241} \mathrm{Am}$ at various applied negative bias voltages and shaping times are shown in Figure 3.

The voltages shown in Figure 3 are absolute values. The ${ }^{241} \mathrm{Am}$ spectra shown in Figure 2 is for negative applied bias voltages, where the negative sign is an indication of the direction of current flow. The peak position becomes more stable as the absolute values of the applied bias voltage increases, and then begins to flatten at about $100 \mathrm{~V}$. The resolution at various applied negative bias voltages and shaping time are shown in Figure 4.

Table 1. Energy resolution for the $59.6-\mathrm{keV}$ gamma line of ${ }^{241} \mathrm{Am}$ at various applied bias voltages and shaping times.

\begin{tabular}{|c|c|c|c|c|c|c|}
\hline \multirow[b]{2}{*}{$\begin{array}{l}\text { Applied } \\
\text { Bias (V) }\end{array}$} & \multicolumn{3}{|c|}{ Channel Number } & \multicolumn{3}{|c|}{ Energy Resolution (FWHM) ${ }^{a}$} \\
\hline & $\begin{array}{c}2-\mu \text { s Shaping } \\
\text { Time }\end{array}$ & $\begin{array}{c}3-\mu s \\
\text { Shaping } \\
\text { Time }\end{array}$ & $\begin{array}{c}\text { 6- } \mu \text { s } \\
\text { Shaping } \\
\text { Time }\end{array}$ & $\begin{array}{c}2-\mu s \\
\text { Shaping } \\
\text { Time }\end{array}$ & $\begin{array}{c}3-\mu s \\
\text { Shaping } \\
\text { Time }\end{array}$ & $\begin{array}{c}6-\mu \text { s Shaping } \\
\text { Time }\end{array}$ \\
\hline-20 & 128 & 146 & 169 & - & - & - \\
\hline-35 & 177 & 204 & 229 & - & - & - \\
\hline-65 & 239 & 265 & 283 & - & - & - \\
\hline-100 & 270 & 290 & 307 & $12.80 \%$ & $11.00 \%$ & $10.80 \%$ \\
\hline-120 & 279 & 298 & 315 & $11.00 \%$ & $9.70 \%$ & $9.60 \%$ \\
\hline-140 & 283 & 304 & 318 & $10.30 \%$ & $9.90 \%$ & $9.20 \%$ \\
\hline-160 & 293 & 307 & 322 & $9.90 \%$ & $8.50 \%$ & $9.06 \%$ \\
\hline-180 & 295 & 309 & 326 & $9.70 \%$ & $8.60 \%$ & $9.10 \%$ \\
\hline-200 & 298 & 310 & 332 & $9.20 \%$ & $8.70 \%$ & $9.30 \%$ \\
\hline
\end{tabular}

a. For applied bias voltages of $-20,-35$ and $-65 \mathrm{~V}$, the energy resolution was not obtained by the software that came with the detection measurement system.

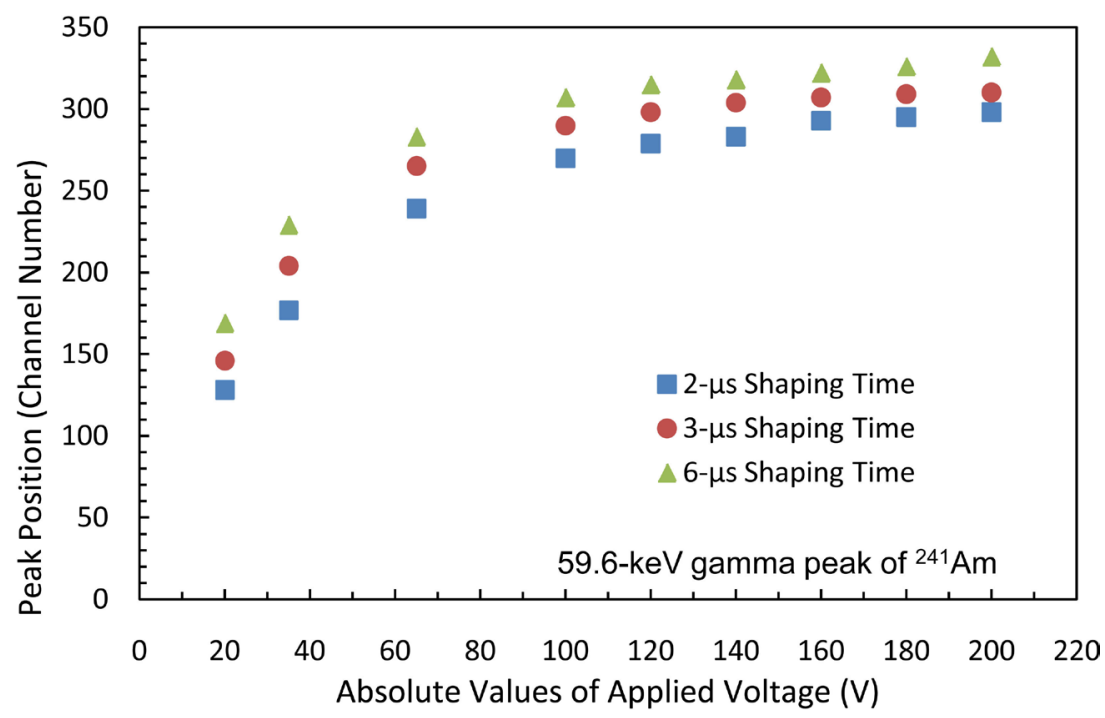

Figure 3. Peak position for the 59.6-keV gamma line of ${ }^{241} \mathrm{Am}$ at various applied negative bias voltages and shaping times. Note: Negative bias is an indication of the polarity, and the voltages shown in graph are absolute values. 


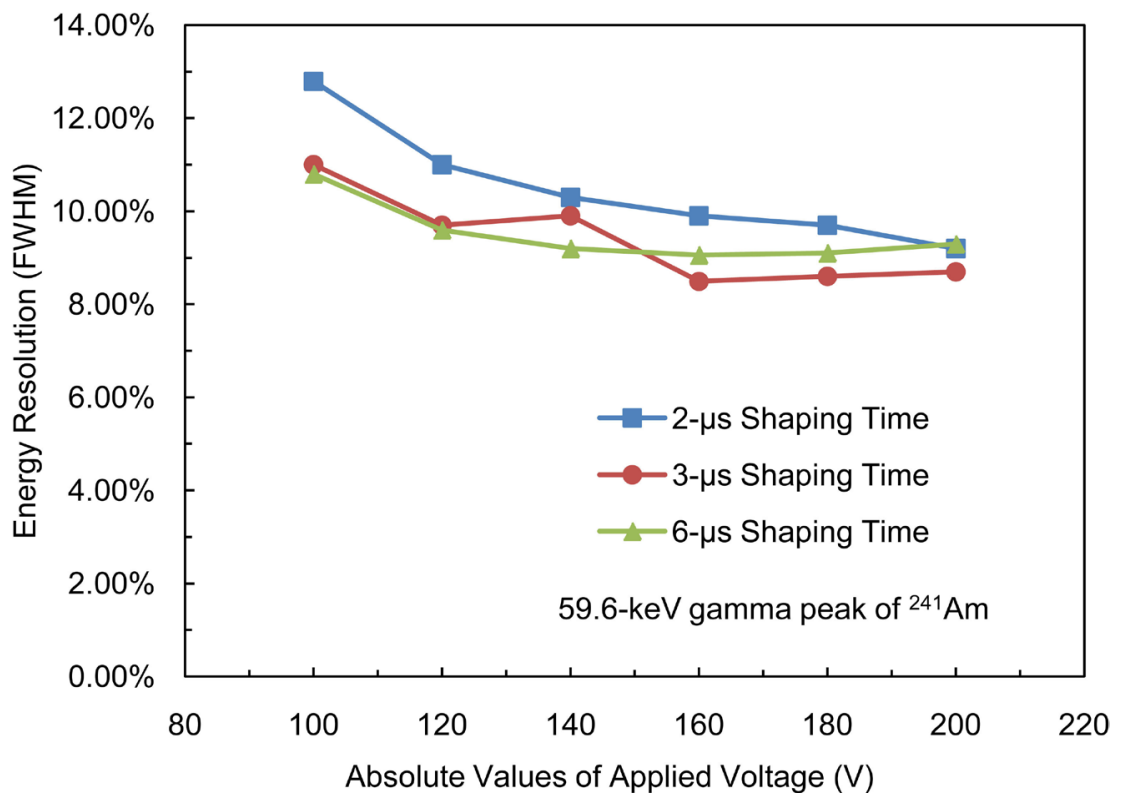

Figure 4. Energy resolution for the $59.6-\mathrm{keV}$ gamma line of ${ }^{241} \mathrm{Am}$ at various applied negative bias voltages and shaping times.

\section{Conclusion}

CZTS has emerged as a very promising semiconductor material for producing cheaper gamma-ray and X-ray detectors for applications at room temperature without cryogenic cooling. The high crystal uniformity of CZTS and near absence of Te inclusions and grain boundary networks have given it great advantage in reducing the cost of semiconductor nuclear detection devices that can operate at room temperature without cryogenic cooling. An energy resolution of $0.9 \%$ for the $662-\mathrm{keV}$ gamma line of ${ }^{137} \mathrm{Cs}$ was recorded at $1800 \mathrm{~V}$ applied bias for a Frisch-grid detector fabricated from a recent CZTS crystal grown by THM [3]. We have characterized a CZTS planar detector over an operating negative bias voltage range of $-20 \mathrm{~V}$ to $-200 \mathrm{~V}$ and amplifier shaping time of 2, 3 and 6 $\mu$ s. The peak position of the $59.6-\mathrm{keV}$ gamma line of ${ }^{241} \mathrm{Am}$ becomes more stable as the magnitude of the applied voltage increases. The energy resolution varied between $8.5 \%$ and $12.8 \%$. The energy resolution was observed to be relatively stable in the $-120 \mathrm{~V}$ to $-200 \mathrm{~V}$ range at $6-\mu$ s shaping time. The variation in peak position began to decrease significantly for bias voltages over approximately $-100 \mathrm{~V}$. Our future work will include the study of the peak position and energy resolution over time. The peak position will be studies with respect to bias voltage. The study of energy resolution over time will be focused on the effect of surface chemical treatments that are in the fabrication of the detector device.

\section{Acknowledgements}

This work was supported in part by the U.S. Department of Energy, Office of Defense Nuclear Nonproliferation Research and Development, the DNN R \& D (NA-22), the National Science Foundation (NSF) HBCU-UP Program through 
award number 1818732, the NSF Louis Stokes Alliances for Minority Participation (LSAMP), and the U.S. Nuclear Regulatory Commission (NRC) through awards number 31310018M0035.

\section{Conflicts of Interest}

The authors declare no conflicts of interest regarding the publication of this paper.

\section{References}

[1] Roy, U.N., Camarda, G.S., Cui, Y., Gul, R., Hossain, A., Yang, G., Vanier, P., Lordi, V., Varley, J., James, R.B., Zazvorka, J., Dedic, V. and Franc, J. (2016) $\mathrm{Cd}_{1-\mathrm{x}} \mathrm{Zn}_{\mathrm{x}} \mathrm{Te}_{1-\mathrm{y}} \mathrm{Se}_{\mathrm{y}}$ : A Potential Low-Cost Alternative to CdZnTe. Technical Report BNL-113882-2017COPR, Brookhaven National Laboratory, Upton, NY, USA.

[2] Roy, U.N., Camarda, G.S., Cui, Y., Gul, R., Yang, G., Zazvorka, J., Dedic, V., Franc, J. and James, R.B. (2019) Evaluation of CdZnTeSe as a High-Quality Gamma-Ray Spectroscopic Material with Better Compositional Homogeneity and Reduced Defects. Scientific Reports, 9, 1620. https://doi.org/10.1038/s41598-019-43778-3

[3] Roy, U.N., Camarda, G.S., Cui, Y. and James, R.B. (2019) Characterization of Large-Volume Frisch Grid Detector Fabricated from As-Grown CdZnTeSe. Applied Physics Letters, 115, 242102. https://doi.org/10.1063/1.5133389

[4] Egarievwe, S.U., Roy, U.N., Goree, C.A., Harrison, B.A., Jones, J. and James, R.B. (2019) Ammonium Fluoride Passivation of CdZnTeSe Sensors for Applications in Nuclear Detection and Medical Imaging. Sensors, 19, 3271.

https://doi.org/10.3390/s19153271

[5] Pérez, J.M., He, Z. and Wehe, D.K. (2000) Stability and Characteristics of Large CZT Coplanar Electrode Detectors. IEEE Transactions on Nuclear Science, 48, 272-277. https://doi.org/10.1109/NSSMIC.2000.949036

[6] Egarievwe, S.U., Chen, K.T., Burger, A., James, R.B. and Lisse, C.M. (1996) Detection and Electrical Properties of $\mathrm{Cd}_{1-\mathrm{x}} \mathrm{Zn}_{\mathrm{x}}$ Te Detectors at Elevated Temperatures. Journal of X-Ray Science and Technology, 6, 309-315. https://doi.org/10.3233/XST-1996-6401

[7] Chun, S.D., Park, S.H., Lee, D.H., Kim, Y.K., Ha, J.H., Kang, S.M., Cho, Y.H., Hong, D.G. and Kim, J.K. (2008) Property of a CZT Semiconductor Detector for Radionuclide Identification. Journal of Nuclear Science and Technology, 45, 421-424. https://doi.org/10.1080/00223131.2008.10875879

[8] Mæhlum, G., Dietzel, K.I., Meier, D., Szawlowski, M., Sundal, B., Vandehei, T., Wagenaar, D. and Patt, B.E. (2007) Study of Cadmium Zinc Telluride (CZT) Radiation Detector Modules under Moderate and Long-Term Variations of Temperature and Humidity. 2007 IEEE Nuclear Science Symposium Conference Record, 2, 1645-1648. https://doi.org/10.1109/NSSMIC.2007.4437315

[9] Roy, U.N., Camarda, G.S., Cui, Y., Gul, R., Hossain, A., Yang, G., Zazvorka, J., Dedic, V., Franc, J. and James, R.B. (2019) Role of Selenium Addition to CdZnTe Matrix for Room-Temperature Radiation Detector Applications. Scientific Reports, 9, Article ID: 232107. https://doi.org/10.1038/s41598-018-38188-w 